\title{
Understanding of consumption behavior at the sports facility approaching stage: Focusing on reservation method, payment method, and inconvenience making a reservation
}

\author{
Kisung Kwon ${ }^{1 *}$ and Hijun $\mathrm{Kim}^{2}$ \\ ${ }^{1}$ Department of Sport Science, Kangwon National University, Kangwon, Korea \\ ${ }^{2}$ Department of Physical Education, Seoul National University, Seoul, Korea
}

\begin{abstract}
[Purpose] This study focuses on accessibility to sports facilities that can be classified into structural leisure constraints. The purpose of this study is to explore exploratory analysis of the types of reservation methods and payment methods, which are the initial stages of consuming sports facilities, and to explore inconveniences that consumers feel when making reservations. [Methods] A quantitative research method was used to derive the results, and data were collected through a questionnaire survey method. The collected data were analyzed by technical statistics focusing on the reservation method, payment method, and inconvenience during reservation. [Results] As a result, it was found that the main types of reservation methods and payment methods were homepage, homepage/telephone, telephone, homepage/app, and account transfer and card payment, respectively. In the case of inconvenience, the procedure was complicated, address and location, and reservation method were identified as the main matters. [Conclusions] Efforts must be made to secure both the convenience and publicity of accessibility at an early stage, such as reservation methods and payment methods for sports facilities.
\end{abstract}

Key words: Sport facility, Leisure constraint, Structural leisure constraints, Reservation method, Transaction method, Inconvenience making reservation

\section{서 론}

\section{연구의 필요성}

2018년 국내 스포츠시설 현황은 2014년, 2016년과 비 교하였을 때 등록체육시설업과 신고체육시설업 모두 큰 변 화 없이 정체된 모습을 보이고 있다. Korea Institute of Sport Science (2019)에 발행한 스포츠산업백서에 따르면

논문 투고일 : 2021.03.18.

논문 수정일 : 2021.05.03.

게재 확정일 : 2021.05.26.

* 교신저자 : 권기성(k.kwon@kangwon.ac.kr)
2018년을 기준으로 총 56,854개소의 체육시설이 운영되 는 것으로 나타났고 그 중에서 등록체육시설업은 511 개소, 신고체육시설업은 56,343개소인 것으로 집계되었다. 비교 를 위해 2016년과 2014년의 통계자료를 살펴보면 전체 스 포츠시설 개소수는 각각 58,321개소, 56,630개소로 확인 되었으며 등록시설업은 각각 511개소와 496개소, 신고시 설업은 각각 57,810 개소와 56,134 개소로 확인되었다.

하지만 Kim, Jung, \& Huh (2016)의 연구에서는 공공체 육시설의 균형 있는 배치를 목적으로 수립된 중장기 계획을 바탕으로 2022년까지도 적정 소요면적 대비 66.3\%까지 밖 에 달성하지 못할 것으로 판단하였다. 이를 기초로 향후에도 스포츠시설은 꾸준히 증가할 것으로 예상하고 있다. 하지만 
스포츠시설 확충에 있어 많은 자원과 시간이 소요되는 만큼 기존 시설에 대한 효용성을 높이기 위한 노력 역시 필요한 시 점이다. $\operatorname{Kim}$ (2017)의 연구에서도 부족한 공공체육시설을 늘리기 위한 재원 마련과 함께 활용도가 높은 시설을 공급하 기 위한 노력도 필요하다는 부분을 강조하고 있다.

이러한 시점에서 여가제약 관련 개념은 스포츠시설의 효 용성 증대에 있어 도움을 줄 수 있다. 이유는 단순히 시설이 많은가 적은가가 아닌 시설 접근에 있어 나타나는 제약 요인 들을 파악하는데 있어 하나의 틀로써 활용할 수 있기 때문이 다. 구체적으로 여가제약은 선호하는 여가 활동에 대한 참 여를 감소시키거나 방해하는 요인으로 정의될 수 있다 (Crawford, Jackson, \& Godbey, 1991; Jackson, Crawford, \& Godbey, 1993; Hwang, Choi, 2012). Crawford \& Godbey (1987)의 연구에서는 여가제약 유형 을 개인적, 대인적, 구조적 측면으로 구분하였으며 개인의 여가에 대한 선호와 실제적 여가 참여 간의 관계를 통해 각 여가제약 유형의 특징을 설명하였다.

해당 연구에서 제시한 유형을 심도 있게 살펴보면 개인적 여가제약 유형은 개인의 여가 참여를 유도하는 특정 여가에 대한 개인적인 선호가 형성되는데 있어 부정적인 영향을 미 친다는 특징이 있다. 예를 들어, 개인의 스포츠 기술에 대한 전문성 또는 자신감의 부족은 개인의 여가에 대한 선호 형성 을 저해하는 것으로 나타났다.

대인적 여가제약 유형은 개인의 여가활동에 대한 선호와 실제적인 여가에 대한 참여 모두에 부정적 영향을 미친다는 특징이 있다. 예를 들어 여가 활동을 같이 할 동반자를 찾는 데 어려움을 겪고 사회와 가정에서의 역할로 인해 표출되는 갈등은 여가에 대한 개인적 선호 형성과 실제적인 여가 참여 모두에 영향을 미칠 수 있다.

마지막으로 구조적 제약은 특정한 여가 활동에 대한 개인 적 선호를 바탕으로 해당 여가 활동에 참여하는데 있어 이를 가로막는 형태로 영향을 미친다. 예를 들어 여가 활동을 즐 길 시설을 찾는데 어려움이 있거나 코로나 19 일부 상황으로 인해 관련된 시설 자체가 모두 폐쇄된 상황에서는 아무리 개 인이 여가에 대한 선호가 형성되었다 하더라고 실제적으로 여가 활동에 참여하는 것이 제한적일 수밖에 없다.

제시된 여가제약 유형 중 스포츠시설은 구조적 여가제약 유형과 연결 지어 설명될 수 있다. 특정 스포츠에 대한 개인 적인 선호가 생긴 경우에도 스포츠시설이 준비되지 않았거 나 접근이 어려운 상황에서는 실제적으로 여가 활동에 참여
할 수 있는 방법이 제한적일 수밖에 없기 때문이다. 더 나아 가 Lee \& Hwang (2012)의 연구에서는 여가활동 비참가에 대한 여가제약 유형을 분석하였으며 시설은 여건, 가치 인 식, 동료, 부담, 가족과 함께 주요한 여가제약 요인으로 확인 되었다. 또한 이러한 여가제약 요인들 중에서도 시설이 가 장 높은 제약요인으로 작용한다는 결과 역시 제시되었다.

주요한 여가제약 요인으로 인식되고 있는 스포츠시설에 내재된 제약 요인들을 살펴보면 Kim, Jung, \& Ko (2017) 의 연구에서는 정보통신기술의 급속한 발전으로 인해 정보 화시대가 고도화되고 있으며 스포츠 관련 정보 역시 하나의 가치 있는 상품으로 인식되고 있다는 부분을 언급하였다. 하지만 여전히 이용 가능한 스포츠시설에 대한 정보를 얻는 데 있어 어려움이 있으며 이는 스포츠시설 접근성 향상에 부 정적인 영향을 미치고 있다는 부분을 강조하였다. 이에 발 전된 정보통신기술을 바탕으로 스포츠시설에 대한 접근성 향상을 위한 통합예약운영관리시스템 구축의 필요성을 제 시하였다. 2017년을 기준으로 공공스포츠시설의 통합예약 운영관리시스템 구축 현황은 지자체 평균 $18 \%$ 를 기록하고 있어 매우 미미한 수준이라는 것을 알 수 있다.

이와 함께 Lee, Shin, Song, Park, \& Sul (2016)의 연구 에서는 스포츠 센터의 효율성을 증대시킬 필요성을 재기하 면서 NFC 통신 기술을 기반으로 하는 스포츠 센터의 운동기 구 예약 시스템 설계 관련 논의를 진행하였다. 한편 Lim \& Yang (2019)의 연구에서는 공공체육시설이 운영하고 있는 온라인을 통한 예약제의 한계에 대한 분석을 진행하였다.

해당 연구들을 살펴보면 예약 부분에 초점을 맞추고 관련 된 문제점을 해결하기 위한 운영적 측면과 기술적 측면에서 기술적 방안 제시와 함께 새로운 형태의 예약 시스템이 가져 올 한계에 대해서도 논의를 진행하고 있다. 이러한 논의를 보다 구체화시키기 위해서는 실제 소비자가 스포츠시설에 접근하고 예약 진행에 있어 나타나는 소비자의 행동 특성을 파악할 필요가 있다. 이를 통해 예약을 포함한 스포츠시설 접근에 있어 나타나는 제약을 보다 효과적이고 효율적으로 극복할 수 있는 방안 모색에 도움이 될 수 있기 때문이다.

\section{연구목적}

이를 배경으로 본 연구는 여가제약 유형 중 스포츠시설과 연결 지어 설명될 수 있는 구조적 여가제약 유형에 초점을 맞 추고자 한다. 더 나아가 스포츠시설에 대한 접근성에 초점을 
맞추어 접근 초기 단계라고 할 수 있는 예약방식과 결제방식을 중심으로 연구를 진행해 보고자 한다. 이에 따른 연구목적은 스포츠시설을 소비하는 초기 단계인 예약방식과 결제방식의 유형을 분석하며 소비자가 예약을 하는데 있어 느끼는 불편사 항을 탐색하는 것이다. 구체적인 연구문제는 첫째 스포츠시설 사용에 있어 활용되는 예약방식 유형은 어떠한가? 둘째, 예약 방식 유형 따라 활용되는 결제방식 형태는 어떠한가? 셋째, 예 약을 진행하는데 있어서 나타나는 불편사항은 무엇인가?

\section{연구방법}

연구목적에 따른 결과 도출을 위해 양적연구방법과 질적 연구방법을 모두 활용한 혼합연구방법을 활용하였다. 설문 지 조사 방법을 통해 자료를 수집하였으며 수집된 자료를 분 석하기 위해 기술통계분석과 교차분석을 활용하였다. 설문 지 문항 구성에 있어서는 질적연구방법을 활용하였다. 질적 연구방법에 대한 신뢰성을 확보하기 위해서는 정확한 연구 기법을 사용하는지가 중요하다. 이로 인해 체계적 분석 과 정을 통해 수집된 자료를 분석하여 결과를 도출하였다. 또 한 타당성 확보를 위해서는 목적하는 부분에 대한 명확한 결 과를 도출하는 것이 중요하기 때문에 자료 수집 대상을 다양 하게 하여 편향성을 줄이기 위해 노력하였다.

\section{연구대상}

연구대상은 예약을 통해 스포츠시설을 사용해본 경험이 있 는 사람으로 설정하였다. 눈덩이 표집(Snowball sampling) 방법을 활용하여 323명을 표본 집단으로 선정하였으며 2018 년 11월 15일부터 11월 30일까지 온라인을 통한 설문조사를 진행하였다. 구체적으로 스포츠 동호회 10개 팀을 대상으로 하였으며 각각 축구 6 팀, 야구 3 팀, 농구 1 팀으로 진행되었다. 이를 위해 각 동호회 총괄 관리를 담당하고 있는 동호회 회원 에게 온라인 형태의 설문지를 전달하였다. 이후 해당 담당자 는 동호회가 현재 사용하고 있는 온라인 대화방에 공유하여 설 문이 진행되었다.

323 개의 설문 응답 중 불성실 응답 또는 스포츠시설 사용 경험이 없는 대상을 제외하고 최종적으로 270개의 응답을 최 종 분석 자료로서 활용하였다. 인구통계학적 정보를 살펴보면 남성과 여성이 각각 252(93.3\%)명과 18(6.7\%)명인 것으로
나타났다. 연령의 경우는 10 대가 4 명( $1.5 \%), 20$ 대가 109 (40.4\%)명, 3대가 152명(56.3\%), 40대가 5명(1.9\%)으로 확인되었다. 〈Table 1〉을 통해 설문 대상자에 대한 인구통계 학 측면의 분석 결과를 제시하였다.

본 연구에서는 실제 스포츠시설 예약 경험이 있는 사람들을 대상으로 하였다. 기존 스포츠시설 관련 연구들의 경우 연구 진행에 있어 소비자 집단을 찾고 집단을 통한 자료 획득의 어 려움이 있어 2차 자료를 사용하는 경우가 많았다. 본 연구에서 는 정확한 목표 집단을 통해 자료를 수집하였다는 부분에서 측 정 시기에 상관없이 수집된 자료에 의미가 있다고 판단된다.

Table 1. Demographic information of the subject

\begin{tabular}{cccc}
\hline \hline Variables & Group & $\mathrm{N}$ & $\%$ \\
\hline Total & Number of Response & 270 & 100 \\
\hline \multirow{2}{*}{ Gender } & Male & 252 & 93.3 \\
\cline { 2 - 4 } & Female & 18 & 6.7 \\
\hline \multirow{2}{*}{ Age } & $10 \mathrm{~s}$ & 4 & 1.5 \\
\cline { 2 - 4 } & $20 \mathrm{~s}$ & 109 & 40.4 \\
\cline { 2 - 4 } & $30 \mathrm{~s}$ & 152 & 56.3 \\
\hline \hline
\end{tabular}

\section{자료수집방법}

설문조사 문항은 예약을 통한 스포츠시설 이용 유무 확인, 예약방식, 결제방식, 예약 시 불편사항, 인구통계학적 정보로 구성하였다. 우선 예약을 통한 스포츠시설 이용 유무 확인을 위해 스포츠시설을 이용한 경험이 있는지에 대한 질문을 포함 시켰으며 '그렇다', '그렇지 않다'로 선택하도록 하였다. '그 렇다’ 로 응답하였을 경우 설문이 진행되고 '그렇지 않다’라고 응답하였을 경우는 설문이 종료되는 형태로 진행되었다.

예약방식의 경우 자신이 스포츠시설을 예약하는데 있어 주 로 사용하는 방법을 중복으로 선택할 수 있게 하였다. 선택지 는 주로 활용되는 방법이라 할 수 있는 홈페이지, 전화, 애플 리케이션(이하 앱), 직접방문, 기타로 구성되었다. 결제방식 은 자신이 스포츠시설 사용에 대한 비용을 지급하는데 있어 주로 사용하는 방법을 중복으로 선택할 수 있게 하였다. 선택 
지는 주요 방법이라 할 수 있는 계좌이체, 카드결제, 현금결 제, 앱 및 홈페이지 결제, 기타로 구성하였다. 스포츠시설 예 약 시 불편사항의 경우 실제 경험한 불편사항을 중복으로 선 택할 수 있게 하였다. 선택지는 결제방법, 예약방법, 주소 및 위치, 홈페이지 이용 어려움, 앱 이용 어려움, 절차 복잡함, 기 타로 구성되었다.

예약방식과 결제방식 관련 질문에 대한 문항을 구성하는데 있어 심층면담을 진행하였다. 대상으로서 스포츠시설 이용 자, 스포츠시설 운영자, 스포츠산업 전문가 각 1 명씩 총 3 명 을 선정하였다. 대상별 1 회씩 스포츠시설을 사용하는데 있어 주로 활용되는 예약방식과 결제방식에 대해 개방된 형태의 질 의를 통해 자료를 수집하였다.

예약 시 불편사항 선택지는 스포츠경영 관련 학부 수업을 듣는 학생 23명을 대상으로 자유 생각 나열 방법을 활용하여 도출하였다. 학생들에게 스포츠시설을 예약하는데 있어서 실 제 경험했거나 예상되는 불편사항을 생각나는 대로 적는 방식 으로 진행되었다.

예약방식, 결제방식, 예약 시 불편사항 관련 문항 구성을 위해 수집된 자료를 분석하기 위해 체계화된 분석 과정을 진 행하였다. 첫 번째 단계에서는 내용분석을 통해 요인을 도출 하였다. 두 번째 단계에서는 도출된 요인을 대상으로 하여 범 주화를 진행하여 유사한 방식 및 불편 사항을 집단화하였다. 마지막으로 각 집단에 대한 항목화를 진행하여 최종 문항을 도출하였다.

각각 심층면담과 자유 생각 나열 방식을 통해 선택지를 구 성한 이유는 우선 문항 도출에 있어 활용 가능한 기존 연구가 제한적이었기 때문이다. 또한 예약방식이나 결제방식이 정보 통신기술의 급속한 발전으로 인해 급격히 변화하고 있고 불편 사항 역시 이와 연계되어 나타나는 상황이어서 주요 방식, 방 법, 불편사항을 가늠하는데 어려움이 있었다. 예약방식, 결제 방식, 예약 시 불편사항에 대해 답변을 하는데 있어 선택지가 한정되어 나타나는 문제점을 보완하기 위하여 기타라는 문항 을 모두 포함시켰다.

\section{자료분석방법}

분석을 진행하는데 있어 응답 내용을 코드화하였다. 중복 답변을 가능하도록 하였기 때문에 2가지를 중복으로 선택한 부분까지 모두 개별적으로 코드화하였다. 3 가지 이상인 경 우는 모두 같은 값으로 코드화하였고 기타의 경우 역시 별도
로 코드화하였다. 예약방식의 경우 1 은 홈페이지, 2 는 전화, 3은 앱, 4는 직접방문, 5는 홈페이지/전화, 6은 홈페이지/ 앱, 7은 홈페이지/직접방문, 8은 전화/앱, 9는 전화/직접방 문, 10 은 앱/직접방문, 11 은 기타, 12 는 3 가지 이상으로 코 드화하였다. 결제방식은 1 은 계좌이체, 2 는 카드결제, 3 은 현금결제, 4 는 앱 및 홈페이지 결제, 5 는 기타, 6 은 계좌이체 /카드결제, 7은 계좌이체/현금결제, 8은 계좌이체/앱 및 홈 페이지 결제, 9는 카드결제/현금결제, 10 은 카드결제/앱 및 홈페이지 결제, 11 은 현금결제/앱 및 홈페이지 결제, 12 는 기타, 13 은 3 개 이상으로 코드화하였다.

예약 시 불편사항에 초점을 맞출 경우 1 은 결제방법, 2 는 예약방법, 3 은 주소 및 위치, 4는 홈페이지 이용 어려움, 5 는 앱 이용 어려움, 6 은 절차가 복잡함, 7 은 기타, 8 은 결제방법 /예약방법, 9는 결제방법/주소 및 위치, 10 은 결제방법/홈 페이지 이용 어려움, 11 은 결제 방법/앱 이용 어려움, 12 는 결제방법/절차가 복잡함 13 은 예약방법/주소 및 위치, 14 는 예약방법/홈페이지 이용 어려움, 15 는 예약방법/앱 이용 어 려움, 16 은 예약방법/절차가 복잡함, 17 은 주소 및 위치/홈 페이지 이용 어려움, 18 은 주소 및 위치/앱 이용 어려움, 19 는 주소 및 위치/절차가 복잡함, 20 은 홈페이지 이용 어려움 /앱 이용 어려움, 21은 홈페이지 이용 어려움/절차가 복잡 함, 22는 앱 이용 어려움/절차가 복잡함, 23 은 3 개 이상으로 코드화가 진행하였다.

코드화된 자료는 우선 예약방식을 기준으로 하여 분류를 진행하였고 다시 각 예약방식 별 결제방식을 구분하여 유형 을 도출하였다. 이를 바탕으로 하여 단계별 기술통계분석을 진행하였다. 첫 번째 단계에서는 예약방식을 대상으로 기술 통계분석을 진행하여 빈도와 비중을 도출하였다. 두 번째 단 계에서는 각 예약방식과 결제방식이 결합된 유형별 기술통 계분석을 진행하였고 이를 통해 각 예약방식 유형에 따른 결 제방식의 빈도와 비중을 확인할 수 있었다. 마지막 단계에서 는 예약방식 별로 예약 시 불편사항에 대한 기술통계분석을 진행하여 결과를 도출하였다. 기술통계분석과 함께 주요 예 약방식을 중심으로 결제방식과 예약 시 불편사항에 대한 교 차분석을 실시하여 실제 예약방식 별로 차이가 있는지를 통 계적으로 검증하였다.

마지막 단계인 예약 시 불편사항 분석에 있어 예약방식을 기준으로만 분석을 진행하였으며 예약방식과 결제방식을 모 두 고려하여 유형화하지는 않았다. 이유는 예약방식과 결제 방식을 모두 고려하였을 때 예약 시 불편사항에 대한 도출 빈 
도가 너무 작아지는 경향이 발생하여 결과로서 의미가 없을 수 있다고 판단했기 때문이다.

\section{연구결과}

\section{예약방식과 결제방식 분석}

예약방식과 관련하여 도출된 결과를 살펴보면 홈페이지 (77회, 28.5\%)가 가장 선호하는 방식으로 나타났으며 그 뒤를 홈페이지/전화(61회, 22.6\%). 전화(43회, 15.9\%), 홈페이지/앱(29회, $10.7 \%$ 로 나타났다. 이외의 방식으로 서 앱(10회, 3.7\%), 홈페이지/오프라인(6회, 2.2\%), 오프 라인(4회, $1.5 \%)$, 전화/오프라인(4회, $1.5 \%)$, 전화/앱(3 회, $1.1 \%)$ 순으로 도출되었다. 3 개 이상의 예약방식을 활 용한다는 응답자 수는 33회, $12.2 \%$ 를 차지하는 것으로 나 타났다.

전체에서 $10 \%$ 이상의 비중을 차지하고 있는 예약방식 을 중심으로 활용된 결제방식을 살펴보면 가장 높은 비중 을 차지하는 예약방식으로 확인된 홈페이지의 경우 $10 \%$ 이상의 비중을 차지하는 결제방식은 계좌이체(35회, 45.5\%), 카드결제(16회, 20.8\%), 계좌이체/카드결제 (11 회, $14.3 \%)$ 순으로 나타났다. 3 개 이상의 결제방식을 사용 하는 응답 수는 7회, 비중은 9.1\%로 도출되었다.

두 번째로 비중이 높게 나타난 홈페이지/전화의 경우 결 제방식 중 $10 \%$ 이상의 비중을 차지하는 방법으로서 계좌 이체(23회, 37.7\%), 계좌이체/카드결제(13회, 21.3\%), 카 드결제(11회, $18 \%$ ) 순으로 나타났다. 3 개 이상의 결제방식 을 사용하는 응답 수는 8 회, 비중은 $13.1 \%$ 로 도출되었다.

세 번째로 높은 비중을 차지한 전화의 경우 $10 \%$ 이상의 비중을 차지한 결제방식은 계좌이체(18회, $41.9 \%$ ), 계좌 이체/카드결제(13회, $21.3 \%$ ), 카드결제(11회, $18 \%$ )인 것 으로 나타났다. 3 개 이상의 결제방식을 사용한 경우는 9회, 20.9\%로 도출되었다.

네 번째로 높은 비중을 차지한 홈페이지/앱을 같이 활용 한 예약방식의 경우 $10 \%$ 이상의 비중을 차지한 결제방식 은 계좌이체(8회, 27.6\%), 계좌이체/카드결제(7회, 24.1\%), 카드결제(6회, 20.7\%), 계좌이체/현금결제(3회, $10.3 \%$ )인 것으로 확인되었다. 3 개 이상의 결제방식을 사
용한 경우는 4회, $13.8 \%$ 로 확인되었다.

마지막으로 3개 이상의 예약방식을 활용한 경우 결제방 식 분석 결과 $10 \%$ 이상 비중을 차지한 방법은 계좌이체(12 회, 36.4\%), 카드결제(4회, $12.1 \%$ ) 순으로 나타났다. 3개 이상은 빈도 8 회, 비중 $24.2 \%$ 로 도출되었다. 〈Table 2〉를 통해 구제적인 결과를 제시하였다.

$10 \%$ 미만의 비중을 차지한 예약방식을 중심으로 살펴 보면 앱의 경우는 계좌이체(4회, 40\%)가, 홈페이지/직접 방문과 직접방문의 경우는 각각 계좌이체(2회, $33.3 \%)$ 와 카드결제(2회, $50 \%$ )가 가장 높은 빈도와 비중을 차지하는 것으로 확인되었다. 전화/직접방문의 경우는 계좌이체/카 드결제와 계좌이체/현금결제 모두 1 회 빈도를 기록하였고 전화/앱은 계좌이체, 카드결제, 계좌이체/현금결제가 모두 1 회 빈도로 나타났다. 3 개 이상의 경우는 계좌이체(12회, $36.4 \%$ )로 가장 높은 빈도와 비중을 차지하였다. 〈Table 3〉 을 통해 자세한 분석 결과를 제시하였다.

결과를 종합하여 보면 홈페이지, 홈페이지/전화, 전화, 홈페이지/앱과 같은 예약방식이 전체에서 $10 \%$ 이상의 비 중을 차지하는 것으로 나타났고 결제방식의 경우는 계좌이 체와 카드결제가 주요하게 사용된다는 것을 확인할 수 있 었다. 결제방식은 기타 응답이 나타나지 않았다. 하지만 예 약방식의 경우는 특정 회사의 메신저와 국내 대표 포털 사 이트 서비스를 활용한다는 응답이 각각 1 개씩 도출되어 앱 과 홈페이지에 각각 포함시켜 자료 분석을 진행하였다.

추가적으로 전체에서 $10 \%$ 의 이상의 비중을 차지하고 있는 홈페이지, 홈페이지/전화, 전화, 홈페이지/앱 예약방 식을 대상으로 교차분석을 진행하였다. 도출된 카이제곱 검정 결과를 살펴보면 값은 29.1 , 유의확률은 .5 로 확인되 어 예약방식에 따른 결제방식 분표가 다르지 않다는 귀무 가설은 기각되지 않았다. 즉 예약방식 별로 결제방식에는 큰 차이가 없는 것으로 나타났다.

\section{예약 시 불편사항 분석}

전체에서 $10 \%$ 이상 비중을 차지한 예약방식을 중심으로 예약 시 불편사항 관련 결과 살펴보면 홈페이지 예약방식의 경우 $10 \%$ 이상의 비중을 차지한 예약 시 불편사항은 절차 가 복잡함(15회, 19.5\%), 주소 및 위치(13회, $16.9 \%$ ), 예약 방법(10회, $13 \%)$ 순으로 나타났다. 3 개 이상의 경우는 12 회, $15.6 \%$ 로 도출되었다. 
예약방식이 홈페이지/전화인 경우 $10 \%$ 이상의 비중을 차지한 예약 시 불편사항은 절차가 복잡함(9회, $14.8 \%$ ), 주소 및 위치(9회, $14.8 \%$ ), 홈페이지 이용 어려움(6회, $9.8 \%$ ) 순으로 도출되었다. 하지만 3개 이상 불편사항이 있 는 경우가 14 회, $23 \%$ 로 가장 높은 빈도와 비중을 차지한 것으로 나타났다.

전화를 통한 예약방식의 경우 예약 시 불편사항 중 $10 \%$ 이상의 비중을 차지한 것은 절차가 복잡함(6회, $14 \%)$, 주소 및 위치(6회, $14 \%)$, 홈페이지 이용 어려움(5, 11.6\%) 순으 로 나타났다. 3 개 이상의 경우는 7 회, $16.3 \%$ 로 나타났다.

홈페이지/앱을 같이 사용한 예약방식의 경우 $10 \%$ 이 상의 비중을 차지한 예약 시 불편사항은 홈페이지 이용 어 려움 (9회, 31\%), 절차가 복잡함 (3회, 10.3\%), 결제방법 (3회, $10.3 \%$ ), 결제방법/예약방법 (3회, 10.3\%)인 것으로 확인되었다. 3 개 이상 선택한 경우는 1 회, $3.4 \%$ 로 나타났 다. 〈Table 4〉를 활용하여 자세한 결과를 제시하였다.

$10 \%$ 미만의 비중을 차지한 예약방식을 살펴보면 직접 방문의 경우는 홈페이지 이용 어려움, 예약방법/홈페이지 이용 어려움, 예약방법/절차가 복잡함, 주소 및 위치/홈페 이지 이용 어려움이 모두 빈도 1 회로 도출되었고 전화/앱 의 경우도 주소 및 위치, 홈페이지 이용 어려움 모두 빈도 1 회로 확인되었다. 3 개 이상의 경우는 예약방법, 절차가 복잡함, 예약방법/주소 및 위치, 예약방법/홈페이지 이용 어려움이 빈도 3 회로 동일하게 나타났다. 앱의 경우는 절 차가 복잡함(2회, 20\%), 홈페이지/직접방문은 주소 및 위 치(2회, $33 \%$ ), 전화/직접방문은 주소 및 위치(2회, 50\%) 가 가장 높은 빈도와 비중을 차지하는 것으로 확인되었다. 〈Table 5〉를 통해 도출 결과를 자세히 제시하였다. 결론 적으로 절차가 복잡함, 주소 및 위치, 예약방법, 홈페이지 이용 어려움이 주요 불편 사항으로 확인되었다.
결제방식 분석 시와 같이 $10 \%$ 의 이상의 비중을 차지하 고 있는 예약방식인 홈페이지, 홈페이지/전화, 전화, 홈페 이지/앱을 중심으로 예약 시 불편사항에 대한 교차분석을 실시하였다. 도출된 카이제곱 검정 결과를 살펴보면 43.3 으로 확인되었고 유의확률은 .9로 나타났다. 이를 통해 결 제방식과 같이 예약방식에 따른 예약 불편 사항 분표가 다 르지 않다는 귀무가설을 기각되지 않았다. 이를 통해 예약 방식에 따른 예약 시 불편 사항도 다르지 않다는 것을 알 수 있다.

예약 시 불편사항 관련 기타로 나온 응답을 예약방식 별 로 살펴보면 홈페이지 유형의 경우 시합 성사 시에만 시설 을 예약할 수 있고 선착순 예약이 진행될 경우 기존 사용자 에게 우선권이 돌아갈 수 있다는 내용이 확인되었다. 전화 유형의 경우는 구장의 절대 공급량이 부족하다는 내용과 사용할 수 있는 스포츠시설을 찾기가 너무 어렵다는 의견 이 제시되었다. 앱을 통한 예약방식의 경우는 대부분 전화 로 예약이 가능하고 시합이 성사되어야 예약이 가능한 부 분이 불편사항이라 언급하였다. 추가적으로 시합과 시설 예약이 통합적으로 이루어질 수 있는 플랫폼이 있으면 좋 겠다는 의견이 나타났다.

홈페이지/전화 예약방식에서는 예약 가능한 스포츠시 설의 공급 수가 턱없이 부족하다는 의견과 홈페이지/앱 유 형에서는 주차가 어렵다는 내용이 확인되었고 홈페이지/ 직접방문 유형의 경우 특정 시간대에 경쟁이 치열하다는 의견이 나타났다. 3 개 이상의 예약방식을 활용하는 유형 의 경우 스포츠시설의 공급이 부족하고, 예약에 있어 불법 적인 방법의 사용이 의심된다는 내용과 함께 특정 시간대 경쟁이 심화된다는 의견이 개진되었다. 시합 성사 시에만 예약이 가능하고 절대 공급량이 부족하며 특정 시간 대 경 쟁이 치열하다는 내용은 중복적으로 나타났다. 
Table 2. Analysis of payment methods by reservation method (more than $10 \%$ proportion)

\begin{tabular}{|c|c|c|c|}
\hline $\begin{array}{l}\text { Reservation method } \\
\quad \text { (Frequency, \%) }\end{array}$ & Payment Method & Frequency & $\%$ \\
\hline \multirow{6}{*}{$\begin{array}{l}\text { Homepage } \\
(77,28.5)\end{array}$} & Bank Account Transfer & 35 & 45.5 \\
\hline & Credit Card & 16 & 20.8 \\
\hline & Bank Account Transfer / Credit Card & 11 & 14.3 \\
\hline & Cash, Bank Account Transfer / Cash, Credit Card/Cash & $2 * 3$ & 2.6 \\
\hline & $\begin{array}{l}\text { Application and Homepage, } \\
\text { Credit Card / Application and Homepage }\end{array}$ & $1 * 2$ & 1.3 \\
\hline & More than 3 methods & 7 & 9.1 \\
\hline \multirow{6}{*}{$\begin{array}{l}\text { Homepage } \\
\text { /Telephone } \\
(61,22.6)\end{array}$} & Bank Account Transfer & 23 & 37.7 \\
\hline & Bank Account Transfer / Credit Card & 13 & 21.3 \\
\hline & Credit Card & 11 & 18.0 \\
\hline & $\begin{array}{l}\text { Bank Account Transfer / Cash, } \\
\text { Credit Card/Application and Homepage }\end{array}$ & $2 * 2$ & 3.3 \\
\hline & $\begin{array}{c}\text { Bank Account Transfer / Application and Homepage, } \\
\text { Credit Card / Cash }\end{array}$ & $1 * 2$ & 1.6 \\
\hline & More than 3 methods & 8 & 13.1 \\
\hline \multirow{7}{*}{$\begin{array}{l}\text { Telephone } \\
(43,15.9)\end{array}$} & Bank Account Transfer & 18 & 41.9 \\
\hline & Credit Card & 5 & 11.6 \\
\hline & Bank Account Transfer / Credit Card & 4 & 9.3 \\
\hline & Cash & 3 & 7 \\
\hline & Bank Account Transfer / Cash & 2 & 4.7 \\
\hline & $\begin{array}{l}\text { Bank Account Transfer / Application and Homepage. } \\
\text { Credit Card / Application and Homepage }\end{array}$ & $1 * 2$ & 2.3 \\
\hline & More than 3 methods & 9 & 20.9 \\
\hline \multirow{6}{*}{$\begin{array}{c}\text { Homepage } \\
\text { /Application } \\
(29,10.7)\end{array}$} & Bank Account Transfer & 8 & 27.6 \\
\hline & Bank Account Transfer / Credit Card & 7 & 24.1 \\
\hline & Credit Card & 6 & 20.7 \\
\hline & Bank Account Transfer / Cash & 3 & 10.3 \\
\hline & Bank Account Transfer / Application and Homepage & 1 & 3.4 \\
\hline & More than 3 methods & 4 & 13.8 \\
\hline
\end{tabular}

* Number: Frequency redundancy indication 
Table 3. Analysis of payment methods by reservation method (Less than $10 \%$ proportion, More the 3 methods)

\begin{tabular}{|c|c|c|c|}
\hline $\begin{array}{l}\text { Reservation method } \\
\text { (Frequency, \%) }\end{array}$ & Payment Method & Frequency & $\%$ \\
\hline \multirow{3}{*}{$\begin{array}{l}\text { Application } \\
(10,3.7)\end{array}$} & Bank Account Transfer & 4 & 40.0 \\
\hline & $\begin{array}{l}\text { Credit Card, Bank Account Transfer/Credit Card, } \\
\text { Application and Homepage, } \\
\text { Bank Account Transfer/Application and Homepage }\end{array}$ & $1 * 4$ & 10.0 \\
\hline & More than 3 methods & 2 & 20.0 \\
\hline \multirow{3}{*}{$\begin{array}{c}\text { Homepage/Place Visiting } \\
\qquad(6,2.2)\end{array}$} & Bank Account Transfer & 2 & 33.3 \\
\hline & Credit Card & 1 & 16.7 \\
\hline & More than 3 methods & 3 & 50.0 \\
\hline \multirow{3}{*}{$\begin{array}{l}\text { Place Visiting } \\
(4,1.5)\end{array}$} & Credit Card & 2 & 50.0 \\
\hline & Bank Account Transfer & 1 & 25.0 \\
\hline & More than 3 methods & 1 & 25.0 \\
\hline \multirow{3}{*}{$\begin{array}{l}\text { Telephone/ } \\
\text { Place Visiting } \\
\quad(4,1.5)\end{array}$} & Bank Account Transfer/Credit Card & 1 & 25.0 \\
\hline & Bank Account Transfer/Cash & 1 & 25.0 \\
\hline & More than 3 methods & 2 & 50.0 \\
\hline \multirow{3}{*}{$\begin{array}{l}\text { Telephone } \\
\text { /Application } \\
\quad(3,1.1)\end{array}$} & Bank Account Transfer & 1 & 33.3 \\
\hline & Credit Card & 1 & 33.3 \\
\hline & Bank Account Transfer/Cash & 1 & 33.3 \\
\hline \multirow{5}{*}{$\begin{array}{l}\text { More } 3 \text { methods } \\
\quad(33,12.2)\end{array}$} & Bank Account Transfer & 12 & 36.4 \\
\hline & Credit Card & 4 & 12.1 \\
\hline & Cash, Bank Account Transfer/Credit Card & $3 * 2$ & 9.1 \\
\hline & $\begin{array}{c}\text { Bank Account Transfer/Cash, } \\
\text { Bank Account Transfer/Application and Homepage, } \\
\text { Credit Card/Cash }\end{array}$ & $1 * 3$ & 3 \\
\hline & More than 3 methods & 8 & 24.2 \\
\hline
\end{tabular}

\footnotetext{
* Number: Frequency redundancy indication
} 
Table 4. Analysis of inconvenience by reservation method (More than $10 \%$ proportion)

\begin{tabular}{|c|c|c|c|}
\hline $\begin{array}{l}\text { Reservation method } \\
\text { (Frequency, \%) }\end{array}$ & Payment Method & Frequency & $\%$ \\
\hline \multirow{9}{*}{$\begin{array}{l}\text { Homepage } \\
(77,28.5)\end{array}$} & Procedure complexity & 15 & 19.5 \\
\hline & Address and location & 13 & 16.5 \\
\hline & How to make a reservation & 10 & 13.0 \\
\hline & Difficulty using the homepage & 5 & 6.5 \\
\hline & $\begin{array}{l}\text { How to make a payment, } \\
\text { Difficulty using the application, } \\
\text { How to make a reservation / Payment }\end{array}$ & $3 * 3$ & 3.9 \\
\hline & $\begin{array}{l}\text { How to make a reservation/Address and location, } \\
\text { How to make a reservation/Difficulty using the homepage, } \\
\text { How to make a reservation/Procedure complexity, } \\
\text { Difficulty using the homepage/Procedure complexity }\end{array}$ & $2 * 4$ & 2.6 \\
\hline & $\begin{array}{l}\text { How to make a payment/Difficulty using the application, } \\
\text { How to make a payment/Procedure complexity, } \\
\text { Address and location/Difficulty using the homepage }\end{array}$ & $1 * 3$ & 1.3 \\
\hline & More than 3 methods & 12 & 15.6 \\
\hline & Others & 2 & 2.6 \\
\hline \multirow{7}{*}{$\begin{array}{l}\text { Homepage } \\
\text { /Telephone } \\
(61,22.6)\end{array}$} & $\begin{array}{l}\text { Procedure complexity, } \\
\text { Address and location }\end{array}$ & $9 * 2$ & 14.8 \\
\hline & Difficulty using the homepage & 6 & 9.8 \\
\hline & How to make a reservation & 5 & 8.2 \\
\hline & $\begin{array}{l}\text { Difficulty using the application, } \\
\text { How to make a payment/How to make a reservation, } \\
\text { How to make a reservation/Address and location, } \\
\text { How to make a reservation/Difficulty using the homepage, } \\
\text { How to make a reservation/Procedure complexity, } \\
\text { Difficulty using the homepage/Difficulty using the application }\end{array}$ & $2 * 6$ & 3.3 \\
\hline & $\begin{array}{l}\text { How to make a payment, } \\
\text { How to make a payment/Address and location, } \\
\text { Address and location/Difficulty using the homepage, } \\
\text { Address and location/Procedure complexity, } \\
\text { Difficulty using the homepage/Procedure complexity }\end{array}$ & $1 * 5$ & 1.6 \\
\hline & More than 3 methods & 14 & 23.0 \\
\hline & Others & 1 & 1.6 \\
\hline
\end{tabular}

* Number: Frequency redundancy indication 
Table 4(continue). Analysis of inconvenience by reservation method (More than $10 \%$ proportion)

\begin{tabular}{|c|c|c|c|}
\hline $\begin{array}{l}\text { Reservation method } \\
\text { (Frequency, \%) }\end{array}$ & Payment Method & Frequency & $\%$ \\
\hline \multirow{7}{*}{$\begin{array}{l}\text { Telephone } \\
(43,15.9)\end{array}$} & How to make a reservation & 8 & 18.6 \\
\hline & $\begin{array}{l}\text { Procedure complexity, } \\
\text { Address and location }\end{array}$ & $6 * 2$ & 14.0 \\
\hline & Difficulty using the homepage & 5 & 11.6 \\
\hline & How to make a reservation/Difficulty using the homepage & 2 & 4.7 \\
\hline & $\begin{array}{l}\text { How to make a payment, } \\
\text { Difficulty using the application, } \\
\text { How to make a reservation/Procedure complexity, } \\
\text { Address and location/Difficulty using the homepage, } \\
\text { Address and location/Difficulty using the application, } \\
\text { Difficulty using the homepage/Difficulty using the application, } \\
\text { Difficulty using the homepage/Procedure complexity }\end{array}$ & $1 * 6$ & 2.3 \\
\hline & More than 3 methods & 7 & 16.3 \\
\hline & Others & 2 & 4.7 \\
\hline \multirow{6}{*}{$\begin{array}{c}\text { Homepage } \\
\text { /Application } \\
(29,10.7)\end{array}$} & Difficulty using the homepage & 9 & 31.0 \\
\hline & $\begin{array}{l}\text { How to make a payment, Procedure complexity, How to make a } \\
\text { payment/How to make a reservation }\end{array}$ & $3 * 3$ & 10.3 \\
\hline & $\begin{array}{l}\text { How to make a reservation, Address and location, } \\
\text { How to make a payment/Address and location }\end{array}$ & $2 * 3$ & 6.9 \\
\hline & $\begin{array}{l}\text { How to make a reservation/Address and location, } \\
\text { How to make a reservation/Difficulty using the homepage }\end{array}$ & $1 * 2$ & 3.4 \\
\hline & More than 3 methods & 1 & 3.4 \\
\hline & Others & 2 & 6.9 \\
\hline
\end{tabular}

\footnotetext{
* Number: Frequency redundancy indication
} 
Table 5. Analysis of inconvenience by reservation method (Less than $10 \%$ proportion, More than 3 inconvenience)

\begin{tabular}{|c|c|c|c|}
\hline $\begin{array}{l}\text { Reservation method } \\
\text { (Frequency, \%) }\end{array}$ & Payment Method & Frequency & $\%$ \\
\hline \multirow{4}{*}{$\begin{array}{l}\text { Application } \\
(10,3.7)\end{array}$} & Procedure complexity & 2 & 20.0 \\
\hline & $\begin{array}{l}\text { How to make a payment, } \\
\text { How to make a reservation, } \\
\text { Address and location, } \\
\text { Difficulty using the homepage }\end{array}$ & $1 * 4$ & 10.0 \\
\hline & More than 3 methods & 2 & 20.0 \\
\hline & Others & 2 & 20.0 \\
\hline \multirow{4}{*}{$\begin{array}{l}\text { Homepage/Place Visiting } \\
\qquad(6,2.2)\end{array}$} & Address and location & 2 & 33.3 \\
\hline & $\begin{array}{l}\text { How to make a payment, } \\
\text { How to make a reservation/Difficulty using the homepage }\end{array}$ & $1 * 2$ & 16.7 \\
\hline & More than 3 methods & 1 & 16.7 \\
\hline & Others & 1 & 16.7 \\
\hline $\begin{array}{l}\text { Place Visiting } \\
\qquad(4,1.5)\end{array}$ & $\begin{array}{l}\text { Difficulty using the homepage, } \\
\text { How to make a reservation/Difficulty using the homepage, } \\
\text { How to make a reservation/Procedure complexity, } \\
\text { Address and location/Difficulty using the homepage }\end{array}$ & $1 * 4$ & 25.0 \\
\hline \multirow{3}{*}{$\begin{array}{l}\text { Telephone/ } \\
\text { Place Visiting } \\
\quad(4,1.5)\end{array}$} & Address and location & 2 & 50.0 \\
\hline & Procedure complexity & 1 & 25.0 \\
\hline & More than 3 methods & 1 & 25.0 \\
\hline \multirow{2}{*}{$\begin{array}{l}\text { Telephone } \\
\text { /Application } \\
\quad(3,1.1)\end{array}$} & $\begin{array}{l}\text { Address and location, } \\
\text { Difficulty using the homepage }\end{array}$ & $1 * 2$ & 33.3 \\
\hline & More than 3 methods & 1 & 33.3 \\
\hline \multirow{5}{*}{$\begin{array}{l}\text { More than } 3 \\
(33,12.2)\end{array}$} & $\begin{array}{c}\text { How to make a reservation, } \\
\text { Procedure complexity, } \\
\text { How to make a reservation/Address and location, } \\
\text { How to make a reservation/Difficulty using the homepage }\end{array}$ & $3 * 4$ & 9.1 \\
\hline & $\begin{array}{c}\text { Address and location, } \\
\text { Difficulty using the homepage, } \\
\text { How to make a reservation/Procedure complexity }\end{array}$ & $2 * 3$ & 6.1 \\
\hline & $\begin{array}{l}\text { How to make a payment/How to make a reservation, } \\
\text { How to make a payment/Address and location, } \\
\text { Address and location/Difficulty using the application }\end{array}$ & $1 * 3$ & 3.0 \\
\hline & More than 3 methods & 9 & 27.3 \\
\hline & Others & 3 & 9.1 \\
\hline
\end{tabular}

\footnotetext{
* Number: Frequency redundancy indication
} 


\section{논 의}

예약방식과 관련지어 도출된 결과를 살펴보면 $10 \%$ 이상 비중을 차지한 방식으로서 홈페이지, 홈페이지/전화, 전화, 홈페이지/앱이 확인되었다. 또한 각 예약방식 별로 결제방식 에 초점을 맞출 경우 계좌이체와 카드결제가 주류인 것으로 나타났다. 이를 종합하여 보면 지금까지도 전통적인 채널인 홈페이지와 전화가 주요 예약방식으로, 계좌이체와 카드결 제가 주요 결제방법으로 활용되고 있다는 것을 알 수 있다.

지금 현재 공급주체별 스포츠시설 규모를 살펴보면 2015 년 말 기준으로 공공체육시설은 22,662개, 민간체육시설은 55,857 개로 확인되어 시설 수만 비교하였을 때는 민간체육 시설이 2배 이상 많다는 것을 알 수 있다(Kim, 2017). 하지 만 세부적인 내용을 확인해보면 사용에 있어 예약이 필요한 시설, 즉 종합체육시설과 같은 경우 공공기관에서 공급하는 시설 면적이 민간 제공 면적과 비교 시 7.7배 정도 크다는 것 을 알 수 있다. 구체적으로 2011년 기준으로 종합체육시설의 경우 공공기관이 공급 주체인 시설의 면적은 약 7.7 백만 평 방미터로 조사되었고 민간은 약 1백만 평방미터로 나타났기 때문이다(Yu, Kim, \& Sung, 2013). 다시 말해 대표적인 주 요 스포츠 동호인들이 예약을 통해 사용하는 시설들의 경우 주로 공공기관이 제공하고 있는 시설이라는 것을 알 수 있다.

공공기관에서 운영하는 스포츠시설들의 경우 서비스 공 정성 확보에 주안점을 두는 경우가 많다(Kim \& Kim, 2017). 예약방식과 결제방식은 서비스 공정성을 확보에 있 어 중요한 부분일 수 있고 이로 인해 공공기관이 공급하고 있 는 스포츠시설의 경우 가장 보편화되어 있는 전통적인 예약 방식과 결제방식을 사용할 수밖에 없는 상황에 놓일 수 있다. Lim \& Yang (2019)의 연구에서는 공공체육시설 인터넷 예 약제의 한계에 대한 분석을 진행하였다. 도출된 결과를 살펴 보면 코트 사용 효율성이 감소(무조건 예약 및 노쇼), 일반 테 니스 동호인의 운동 기회가 감소(기존 동호회 예약 선점), 스 포츠 소외계층의 운동권 침해(실버 스포츠인)와 같은 한계가 나타날 수 있다는 결과가 도출되어 서비스 공정성에 대한 부 분을 부연 설명해 주고 있다.

예약을 하는데 있어 확인된 불편사항에 초점을 맞출 경우 절차, 주소 및 위치, 예약방법, 홈페이지 이용이 주요 불편사 항으로서 도출되었다. 스포츠시설에 관한 기존 연구를 살펴 보면 이용 시 문제점으로 예약과 같은 이용절차의 어려움이 도출되었다. 또한 비 물리적 측면 중에서는 개선이 필요한 사
항으로서 온라인 예약 시스템 등 이용절차의 편리성에 대한 재고가 필요한 것으로 확인되었다(Kim, Jung, \& Ko, 2017). 이를 통해 본 연구에서 도출된 결과가 기존 연구에서 제시하 고 있는 연구결과와 유사한 맥락에 있다는 부분을 알 수 있다.

관련 연구를 살펴보면 스포츠산업 내에서 이미 홈페이지 이용에 대한 불편사항을 인지하고 앱을 통해 이를 보완하려 는 모습이 나타나고 있다는 것을 알 수 있다. Nam \& Lee (2020)의 연구에서는 미국 프로야구와 프로농구 리그에서는 각각 소속된 40 개와 30 개 구단 모두 공식적인 앱 서비스를 제공하고 있다는 결과를 제시하였다. 또한 영국 프리미어리 그에 소속되어 있는 모두 구단의 경우도 공식 앱을 활용하여 팬과 소통하고 있다는 부분을 언급하였다.

해당 연구에서는 앱의 활용성이 높아지고 있는 이유에 대 해서는 우선 프로구단들이 팬과의 소통에 대한 중요성을 높 게 인식하고 있기 때문인 것으로 설명하였다. 또한 모바일이 주요 소통 수단으로 변화하고 있는 최근 상황에 대응하여 사 용자 편의성을 높이기 위해 시간과 기술, 자본 투자 때문이라 는 부분을 강조하였다. 본 연구에서도 홈페이지와 앱을 같이 사용하는 유형의 경우 홈페이지 이용이 불편하다는 응답이 9 회, $31 \%$ 로 도출되었으며 이는 홈페이지에 대한 불편사항을 앱 사용을 통해 보완하는 것으로 해석될 수 있어 앞선 연구에 서 언급한 부분을 부연 설명하는 결과라 할 수 있다.

본 연구를 통해 도출된 결과가 학문적으로 가지는 의미는 우선 여가제약 중 구조적 여가제약 유형과 관련하여 좀 더 심 도 있는 연구 진행에 있어 발판을 마련한 것이다. 본 연구는 스포츠시설과 연계되어 설명할 수 있는 구조적 여가제약 요 인과 그 중에서도 초기 접근 단계에 집중하여 결과를 도출하 였다. 구체적으로 예약방식과 결제방식과 관련하여 도출된 결과들은 추후 구조적 여가제약 관련 연구를 진행하는데 있 어 중요한 연구의 방향성을 제시하고 있다.

이와 함께 본 연구에서는 예약 시 나타날 수 있는 불편사항 에 초점을 맞추었다. 이렇게 도출된 결과가 가지는 학문적 의 미는 사람들이 여가활동에 대한 만족도 연구에 바탕이 될 수 있다는 부분이다. 비록 본 연구에서 초점을 맞춘 부분은 예약 시 나타나는 불편사항이지만 예약 역시 서비스 만족도에 영 향을 미칠 수 있는 중요한 부분이다. 이러한 불편사항을 발판 으로 하여 여가활동에 대한 서비스 만족도와 관련된 변인들 을 도출해 내는데 있어 도움이 될 수 있다.

실무적으로는 연구를 통해 도출된 예약방식, 결제방식, 예 약시 불편사항을 서비스 만족도 재고를 위한 방안을 모색하는 
데 있어 적용해 볼 수 있다. 우선적으로 기존의 사용자들이 사 용하고 주로 사용하고 있는 예약방식과 결제방식을 좀 더 용이 하게 이용할 수 있도록 서비스를 개선할 수 있다. 또한 이용에 대한 보편성을 해치지 않은 범위에서 보다 편의성이 높은 예약 및 결제방식을 고민해 볼 수 있다. 더 나아가 예약 시 불편사항 들을 참고하여 보다 자세한 정보를 제공하거나 이용에 편리성 을 높여나가는 방향으로 운영 체계를 바꾸어 나갈 수 있다.

\section{결론 및 제언}

본 연구의 목적은 스포츠시설을 소비하는 초기 단계인 예 약방식을 중심으로 결제방식과 소비자가 예약을 하는데 있어 느끼는 예약 시 불편사항을 탐색적으로 확인하는 것이다. 결 과 도출을 위해 혼합연구방법을 활용하였다. 설문 문항을 도 출하는데 있어 질적연구방법을 활용하였으며 양적연구방법 인 설문지 조사 방법을 통해 자료를 수집하였으며 수집된 자 료는 기술통계분석과 교차분석을 통해 결과를 도출하였다.

결과적으로 예약방식의 경우 홈페이지, 홈페이지/전화, 전화, 홈페이지/앱이 주로 활용되었고 결제방식은 계좌이체 와 카드결제가 많이 사용되는 것으로 나타났다. 불편 사항의 경우는 절차가 복잡함, 주소 및 위치, 예약방법이 주요 사항 으로 도출되었다. 다만 교차분석 결과를 살펴보면 주요 예약 방식 간의 결제방식과 예약 시 불편사항에 대한 유의한 차이 는 없는 것으로 나타났다.

본 연구를 진행하는데 있어 제한점은 우선 공공시설과 민 간시설을 구분하지 않은 부분이다. 본 연구에서는 두 가지 특 징을 지닌 공간에 대해 구분 없이 자료를 수집하고 수집된 자 료를 분석하였다. 공공시설과 민간시설의 경우는 이용자들 에 제공하는 시설 형태와 서비스 특징에 있어 다른 속성이 있 을 수 있기 때문에 이를 구분한 연구가 추후에 진행될 필요가 있다.

이와 함께 나타난 제한점은 연구 대상 확보에 어려움이 있 어 표본집단의 수가 270 여 명에 그쳤다는 부분이다. 또한 설 문 대상의 연령과 성별 비율이 각각 남성과 20 30대로 집중 되었다는 측면이다. 연령이 집중된 이유는 온라인을 통해 자 료 수집하는 경우 나타날 수 있는 한계 때문이라 판단할 수 있다. 성별의 경우는 기본적으로 여성 참여자가 절대적으로 적은 상황 때문에 나타난 결과로 생각된다. 이로 인해 추후 연구에서 연구 대상 확대시켜 나갈 필요가 있으며 이를 통해
관련된 연구결과를 보다 일반화 시키는데 도움이 될 것으로 판단된다.

또한 다양해지고 있는 예약방식과 결제방법을 모두 포함 하지 못했다는 것이 제한점으로 남아 있다. 전문가 심층면담 과 자유 생각 나열과 같은 방법으로 대표적인 예약방식, 결 제방식, 예약 시 불편사항들을 확인하여 문항을 구성하고 이 를 통해 설문을 진행하였다. 하지만 최근 다양한 형태의 예 약방식과 결제방식들이 시시각각 변화하고 새롭게 나타나고 있어 이를 대상으로 한 추가적인 연구가 필요하다.

여가 활동으로서 스포츠에 대한 수요는 점차 늘어나는 추 세이다. 하지만 한정된 국토 공간 속에서 스포츠시설을 확충 해 나갈 수만은 없는 상황이다. 이에 따라 스포츠시설에 대 한 효용성을 높일 수 있는 방법 모색이 필요한 시점이다. 하 지만 스포츠시설에 대한 공공성 역시 고려되어야만 한다. 이 로 인해 스포츠시설에 접근 초기 단계라 할 수 있는 예약방식 과 결제방식에 대한 편리성과 공공성을 모두 확보하기 위한 노력이 반드시 필요하다.

\section{참고문헌}

Crawford, D. W. \& Godbey, G. (1987). Reconceptualizing barriers to family leisure. Leisure sciences, 9(2), 119-127.

Crawford, D. W., Jackson, E. L., \& Godbey, G. (1991). A hierarchical model of leisure constraints. Leisure sciences, 13(4), 309-320.

Hwang, S. \& Choi, H. (2012). Testing the mediated effects of leisure constraints negotiation on recreation specialization among alpine skiers. Journal of leisure and recreation studies, 36(2), 41-65.

Jackson, E. L., Crawford, D. W., \& Godbey, G. (1993). Negotiation of leisure constraints. Leisure sciences, 15(1), 1-11.

Kim, M. (2017). 생활체육 공공인프라, 변화가 필요하다(Korean Title Only). Sport Science, 139(SUMMER), 48-51.

Kim, M. O., Joung, Y. J., \& Huh, J. J. (2016). An Empirical Study on Factors Affecting the Operating Balance and Use of Public Sports Facilities. Korean Journal of Sports Science, 27(4), 797-809.

Kim, M., Joung, Y., \& Ko, J. (2017). A study on the integrated management system of public sports facilities based on 
IoT technology. Korean Journal of Sport Science, 28(4), 963-977.

Kim, Y. \& Kim, S. (2017). The Effect of Service Justice of Public Leisure Facility on Leisure Satisfaction and organization Trust. The Korean Journal of Sport, 15(2), 237-245.

Korea Institute of Sport Science (2015). 2014 Sport Industry Whitebook.

Korea Institute of Sport Science (2017). 2016 Sport Industry Whitebook.

Korea Institute of Sport Science (2019). 2018 Sport Industry Whitebook.

Lee, K., Shin, Y., Song, H., Park, J., \& Sul, S. (2016). Design and Implementation of Exercise Machines Reservation System for Fitness Center. Journal of the Korea Institute of
Information and Communication Engineering, 20(3), 599-606.

Lee, M.. \& Hwang, S. (2012). Examination of Leisure Constraints and Leisure Constraints Negotiation Strategy for Non-participants in Leisure. Korean journal of physical education, 51(3), 263-272.

Lim, S. \& Yang, W. (2019). Exploring limitations of internet-reservation system for public sport facilities: Case study on 'Sejong City First Town Tennis Club. Korean Society for the Study of Physical Education, 24(3), 203-216.

Nam, J. \& Lee, J. (2020). Influence of Affordance and Flow on Satisfaction on Korean Professional Sports Team's Application. The Korean Journal of Sport, 18(1), 701-711.

Yu, J., Kim, S., \& Sung, J. (2013). 공공스포츠시설이 민간스 포츠시설의 운영에 미치는 영행(Korean Tittle Only). Working Report. Korea Institute of Sport Science. 


\title{
스포츠시설 접근 단계의 소비 행동 탐색: 예약방식, 결제방법, 예약 시 불편사항을 중심으로
}

\author{
권기성 ${ }^{1}$, 김희준 ${ }^{2}$ \\ ${ }^{1}$ 강원대학교 조교수 \\ ${ }^{2}$ 서울대학교 박사과정
}

[목적] 본 연구는 구조적 여가제약 유형으로 구분될 수 있는 스포츠시설 접근성에 초점을 맞추고 있다. 이 에 따른 연구 목적은 스포츠시설을 소비하는 초기 단계인 예약방식과 결제방법의 유형을 탐험적으로 분석하며 소비자가 예약을 하는데 있어 느끼는 불편사항을 탐색하는 것이다. [방법] 결과 도출을 위해 양적연구방법을 활용하였으며 설문지 조사 방법을 통해 자료를 수집하였다. 수집된 자료는 예약방식, 결제방법, 예약 시 불편 사항을 중심으로 기술통계분석을 진행하였다. [결과] 결과적으로 예약방식과 결제방법의 주요 유형으로서 각 각 홈페이지, 홈페이지/전화, 전화, 홈페이지/애플리케이션과 계좌이체와 카드결제가 주류인 것으로 나타났 다. 불편 사항의 경우는 절차가 복잡함, 주소 및 위치, 예약방법이 주요 사항으로 도출되었다. [결론] 스포츠시 설에 대한 예약방식과 결제방법과 같은 초기 단계의 접근성에 대한 편리성과 공공성을 모두 확보하기 위한 노력이 반드시 필요하다.

주요어: 스포츠시설, 여가제약, 구조적 여가제약, 예약방법, 결제방법, 예약 시 불편사항 